\title{
THE INTEGRATION OF INTRAPRENEURSHIP INTO A PERFORMANCE MANAGEMENT MODEL
}

\author{
THABO WL FOBA \\ Vuyani @mweb.co.za \\ DAWIE DE VILLIERS \\ Department of Human Resource Management \\ University of Johannesburg
}

\begin{abstract}
This study aimed to investigate the feasibility of using the dynamics of intrapreneurship to develop a new generation performance management model based on the structural dynamics of the Balanced Score Card approach. The literature survey covered entrepreneurship, from which the construct, intrapreneurship, was synthesized. Reconstructive logic and Hermeneutic methodology were used in studying the performance management systems and the Balanced Score Card approach. The dynamics were then integrated into a new approach for the management of performance of intrapreneurial employees in the corporate environment. An unstructured opinion survey followed: a sample of intrapreneurship students evaluated and validated the model's conceptual feasibility and probable practical value.
\end{abstract}

Key words: Intrapreneurship, performance management

It is common wisdom that technological advances in the fields of communication such as digitalization, satellite transmission, and intercontinental transport have, over the past two decades, facilitated the trend towards globalization. Slabbert et al (2003:2 $20)$ concur that one of the consequences of globalisation, with markets no longer limited to specific geographic regions, products no longer specific to single buying or geographic populations, and with most businesses avariciously pursuing the global market, has been an increasing demand for competitiveness within organisations. A further consequence is that organisations are faced with constraints on available resources, both human and capital, as the need for innovation, quality and competencies is amplified in endeavours for competitive advantage and compliance with customer requirements.

Globalisation and its consequential outcomes have had an inordinate impact on the world of work. One of the consequences has been a trend toward virtual employment where technologically complex cell phones, wireless connected laptop computers, and air travel possibilities have enabled employees to communicate and interact globally. This, in turn, facilitated the servicing of national and international customers and markets. Slabbert et al (2003:2-20) support this view, pointing out that technological developments and progress over the past few years have changed the way in which work is done and organised as the world moves towards virtual offices, workers and organisations.

Another development flowing from globalisation is the demise of the traditional production environment and the growth of value added economic activities. This in turn has led to questions about the continued viability of the traditional basis of employment. Traditionally, management consisted of instructing the employee about what work had to be done, how it had to be done and when it had to be done, but in the new world of work, innovation, creativity, proactiveness, initiative, risk taking, personal decision making, flexibility and mobility dictate success. Thus, the traditional employment relationship and management style may no longer be feasible.

Finally, changes in work place and work method have raised questions about the continued feasibility of traditional performance measurement systems and approaches. As a result, alternatives to the traditional human characteristic or performance measure based approaches have been sought. New approaches to performance management have been suggested by academics such as Norton and Kaplan (2005), and later Rampersad (2003), who created the various Balanced Score Card methodologies.
This deviation indicating recognition of the need for a new approach to performance measurement and represents the first steps in the direction of addressing the dynamics of the new world of work. However, the conceptual leap to recognising the increasingly important role of intrapreneurship in the corporate environment and the need to be able to measure the intrapreneurial behaviour as a part of the new management dynamics of the global business environment had not yet been made.

\section{Intrapreneurship}

Economists have long recognised the role of entrepreneurial initiative as a generator of greater economic activity and its value in sustaining economic stability, usually outside of the traditional production based environment. Audretsch (2004) declares that entrepreneurship is the engine of economic and social development throughout the world. Antoncic and Hisrich (2003) state that the initial research into, and view of entrepreneurship focused on the initiatives taken by individuals with regard to new business venture creation. They espouse the view that, whereas entrepreneurship gives life to small businesses and individual enterprises, the so-called 'knock-on effect' is that these small businesses often grow into large production based corporations. Little research has, however, been done on the role of entrepreneurship, or rather intrapreneurship, within the already existing large corporates. Equally little research exists with regard to the interface between entrepreneurship and the emerging corporates that are value-added based rather than production based and which increasingly have to maintain their competitiveness in the global environment.

A new economic paradigm recognises that, while there is a need for new entrepreneurs to emerge and generate new economic activity which will eventually develop into larger businesses, thereby generating capital growth and employment opportunities, a substantial need also exists for entrepreneurship within the new knowledge-based, value-added business organizations of the global economic environment.

Antoncic and Hisrich (2003) recognise this development and point out that economists are now increasingly transferring their attention to the role and contribution of entrepreneurs within the larger organisation. They refer to these as "intrapreneurs", emphasising that it is characteristic of the intrapreneur to behave as an entrepreneur and recognising entrepreneurs according to their economic behaviour. Kuratko et al (2001) concur that entrepreneurship should in future include acts of creation, renewal or innovation with regard to economic or business activities that occur within or outside an organisation, 
as well as activities that take place in an established organisations and that they describe these as corporate entrepreneurship or intrapreneurship.

Relevant research and publications reveal a common finding that there are four primary characteristics which identify entrepreneurship, and mutatis mutandis also intrapreneurship. These characteristics are: (1) corporate or new business venturing, (2) proactiveness, (3) self renewal or transformation and (4) competitive aggressiveness. In addition it has been become common cause that there are a further five secondary characteristics that can be found in most, if not all, intrapreneurs. These are (1) strategy, (2) innovativeness, (3) autonomy, (4) risktaking, and (5) team-building.

The classification of primary and secondary characteristics is fairly arbitrary and, for purposes of this study, all nine of these characteristics were used as a set of common variables for the integration into an envisaged conceptual model for the management of intrapreneurial performance. It was obvious that these nine variables would be the critical items to be 'measured' or evaluated when intrapreneurial behaviour in organisations is evaluated.

In addition to the above mentioned nine variables, research has identified that there are a number of organisational dynamics that, although they cannot in any way be classified as intrapreneurial characteristics, but which in fact facilitate, promote and enhance intrapreneurial behaviour. It has been suggested that these factors actually 'enable' the exercise of intrapreneurial behaviours in the corporate environment, and must therefore also be taken into account when intrapreneurial behaviour in organisations is evaluated. For the purposes of this investigation these factors have, therefore, been classified as 'enablers'. They are: vision, mission, objectives, strategy, culture, structure, risk-taking, team work, autonomy, employee involvement, processes, resources, reward systems, competitiveness, innovativeness, proactiveness, and learning.

\section{Performance Management}

Traditionally performance management in production based organisations could readily be achieved by first identifying critical performance variables such as the number of units of productions, and simply evaluating the achievement of certain production output against a predetermined standard or benchmark. Another approach to performance management in the traditional environment is the evaluation of the degree to which employees respond positively to the direct supervision by their managers, where they are required to carry out instructions meticulously and closely adhere to prescribed operational methodology.

The management of performance in the knowledge based organisations howeverdiffers from that of traditional organisations in that competitiveness and responsiveness to client needs are critical considerations. Templer (2000) suggests that the output of intrapreneurs in knowledge-based competitive organisations can probably not be measured in units of production or employee response to prescription in terms of instruction, but will have to be assessed in terms of added value outputs. It is almost axiomatic that value added outputs are exceptionally difficult to measure accurately. Performance management will therefore undoubtedly become a critically important challenge facing management as organisations transform into knowledgebased global organisations. It is safe to deduce that a reengineered approach to performance management has already become essential to facilitate the management of employees in the globally competitive environment.

This assumption regarding the critical need for transformation in the approach to performance management in 'new age' organisations is exacerbated by the paradigm of a 'roving, virtual' operator, working from a virtual office, whose work performance can be judged only by his or her value added 'outputs' which are often not really quantifiable in the short term. This begs the question regarding the viability of direct supervision and control. It further suggests that a totally fresh view of, and approach to, performance management is an imperative.

\section{RESEARCH DESIGN}

\section{Research Approach}

In contemporary qualitative research the trend is that researchers clarify their scientific beliefs and values prior to deciding on the research design. Accordingly, it is prudent to reflect on the ontological and epistemic rationale, which underpinned the study.

\section{Scientific Values}

Ontology refers to a person's views on the nature of things in the social world (Schurink, 2004). According to Bryman (2004: 19) ontological assumptions and commitments shape the ways in which research questions are formulated and the research is carried out. The views of a group of students and academics, who tested the veracity of the model created as a consequence of this study, shaped the social reality about intrapreneurial principles and the performance management as well as reflected the ontological context of the study.

Epistemology refers to what a person regards as knowledge or evidence of things in the social world (Schurink, 2004). With reference to this study, document analysis, unstructured questionnaires were used to capture the social views and experiences of the authors, students and academics. Their knowledge, experience and perceptions on the concepts of entrepreneurship/intrapreneurship and performance management therefore provided an epistemological basis for developing new theories and models for the study. Having reflected on the ontological and epistemic rationale underpinning the study, it is therefore prudent to present a synopsis on the research approach.

As the intention of the study was to build a conceptual model, the definition of what constitutes a model, needed to be defined. Mouton (1996: 196) stresses that the key issue to bear in mind when either studying or using models is that they do not purport to be anything more than partial representations of given phenomena. In this study this description of a "model" was adopted as the intention was to provide a representation of what constitutes intrapreneurship, as well as a model depicting a typical intrapreneurial performance management system.

The research was guided by the reconstructive logic process, when constructing the envisaged conceptual model. Literature was used in reconstructing two concepts in order to integrate them using an inductive logical reasoning process that is contained in the hermeneutic methodology proposed inter alia by Neuman (2003: 140). The methodology employed in gathering and interpreting the data for this study is described below.

\section{Research Methodology}

The premise from which this investigation departed with regard to the methodology employed was that generally, methodological reasoning dictates that: (1) where there is little or insufficient literature on the subject being investigated, an empirical examination would be required in order to generate the necessary data; and (2) conversely, where a mass of data already exists, an 'interpretive analysis' may be utilised to synthesize the common knowledge generated by this mass of data, to clarify the actual common meaning or discover new meanings of constructs, or some 'reconstructive logic' may be used to generate new constructs. 
The availability of extensive literature and research reports on the constructs, intrapreneurship and performance management, facilitated the choice of the interpretive methodology which was suggested for the first phase of the study. The intention of the first phase of the study was to conduct a literature survey on the above constructs and synthesise the data to generate new understanding and reconstructive logic to create a new construct which would lead to the emergence of a conceptual model. The second phase would test the veracity of the conceptual model in terms of its validity, theoretical or academic value and practical value, by soliciting nominal data by means of an opinion survey of a sample of relevant respondents. The methodology employed for the two phases of the study is explained below.

\section{Phase One}

The data for Phase One, which formed the main body of this investigation, mainly comprised literature and research publications dated between 1998 and 2007, on the constructs; intrapreneurship and performance management. It was assumed that such articles would provide the most developed and recent data, particularly on intrapreneurship.

\section{Sample}

The sample, from which the data of Phase One was solicited, constituted all the authors of all the publications on the subject of entrepreneurship, intrapreneurship and performance management, which was relied on in the interpretive analysis.

An extensive literature survey was conducted on literature, books and periodicals and on academic as well as research library bases on the internet, regarding the constructs intrapreneurship and performance management, in terms of the prescribed dates (between 1998 and 2007). The data derived from the publications from the internet library bases was down-loaded and read. Only the data which was extracted from the publications was referenced in this research report. These were mainly publications which best summarised the required data or presented them in a manner that facilitated a better integration of opinions and facts or the discovery of new knowledge.

\section{Data Collection}

As this phase of the investigation relied on the available literature to extract data from publications, the literature survey method was employed. According to Neuman (2000: 33) every researcher collects data using one or more techniques. The techniques may be grouped into two categories: quantitative methodology, which involves the collection of data in the form of numbers, and qualitative, which refers to the collection of data in the form of words or pictures.

This phase of the investigation utilised the qualitative method of collecting data. This was done by means of identifying academic and research bases on the internet, downloading the extracted data and storing them in marked files, which were categorised according to the constructs entrepreneurship, intrapreneurship and performance management. The collection of the above data led to the analysis, which is explained below.

\section{Data Analysis}

The analysis of the data for Phase One of this study was guided by the opinions expressed by Neuman (2003) and Schwandt (2003).

According to Neuman (2003: 76), documentary or text analysis is ordinarily interpretive, as its objective is to seek to extract meaning from the text. This interpretive approach often typifies a qualitative method of research. As the intention of the study was to interpret the published opinion and research findings of previous authors on intrapreneurship and performance management, the hermeneutic methodology, was felt to be best suitable, as its analysis is meant to discover meaning or explain a lot of discrete but interrelated data.
Neuman (2003:76) describes hermeneutics as a methodology which "emphasises a detailed reading or examination of text, which could refer to a conversation, written words or pictures". According to Neuman, a researcher conducts a reading to discover meaning embedded within text. Each reader brings his or her subjective experience to the text. When studying the text, the researcher/reader tries to absorb or 'get inside', to adopt the viewpoint that it presents as a whole, and develops a deep understanding of how its parts relate to the whole. True meaning is rarely simple or obvious on the surface; one reaches it through a detailed study of the text, contemplating its many messages and seeking the connections through its parts.

This investigation was guided by the criteria recommended by Madison (1990) and adapted by Whittaker (2001) for using the hermeneutics methodology. Madison developed his principle for the purpose of the validation of a specific text. Whittaker (2001) adapted these principles for the purpose of working with a multitude of texts from a multitude of authors. As this study focuses on a multitude of texts from various authors, these criteria seemed the most appropriate. The guiding principles that Madison lists are: coherence, comprehensiveness, penetration, thoroughness, appropriateness, contextuality, agreement, suggestiveness and potential (Madison, 1990).

\section{Phase Two}

It was anticipated, through a structured research methodology utilised in the main body of this investigation that the interpretation of data in Phase One would yield data in the form of a conceptual model that would have to be validated. Accordingly, it was decided that an unstructured opinion survey methodology, be utilised on data solicited from sample of respondents who were exposed to entrepreneurial projects and studies, would also yield findings that could confirm the veracity of the conceptual model.

\section{Sample}

In order to test the veracity of the conceptual model it was felt that such test would have to be conducted by a sample of highly credible respondents. The appropriate sample was found amongst a group of 21 students and academics from the Faculty of Economics and Management Sciences at the University of Western Cape, in South Africa, who were involved in entrepreneurial studies and projects under the guidance of their academic leaders and the auspices of the University. This group was selected because it was assumed that as they were involved in studies and projects of entrepreneurship, they would have the academic understanding and the theoretical, as well as the practical, knowledge of entrepreneurship. Thus, their opinions would be relatively 'valid' and 'reliable'.

This sample could be regarded as a 'representative sample' because they are representative of a profile of students and academics of entrepreneurship within a University.

\section{Data Collection}

The data for this second phase of the study was collected by means of unstructured questionnaires which were administered to a sample of students and researchers of entrepreneurship. According to Miller and Salkind (2002: 51), the collection of data is a crucial step in the execution of a good research design, because the quality of the research often rests upon the quality of the data

The questionnaires solicited only nominal data, to test the veracity of the conceptual model which would emerge from the first phase of this study. Although the data are nominal, they are valuable in that they represent the valid and reliable opinions of a sample of respondents involved in entrepreneurial studies and projects. 


\section{Data Analysis}

In the analysis of the nominal data collected during the opinion survey, use was made, largely, of histograms, in order to determine the implications of the views of the respondents. According to Neuman (2000: 317), a histogram is a type of graphical representation of numerical data which may be nominal, ordinal, interval, or ratio-level data. Neuman op cit., further explains that histograms are usually upright bar graphs of interval or ratio data.

The nominal data contained in the questionnaires was analysed by grouping them into 15 mutually exclusive categories in accordance with the questions on the questionnaires which had elicited various responses from the respondents. Twelve of the categorised questions related to an assessment whereby the respondents rated aspects of the conceptual model according to a scale of between 1 and 10, where 1 reflected a very low score and 10 represented a very high score. Three of the categorised questions solicited responses which gave a negative or positive answer to inquiries about some aspects of the conceptual model.

The responses to the twelve questions, which were in the form of raw scores, were then transcribed and converted to bar charts, in order to represent the ratings by the respondents. These ratings had to be above a score of 5 , which is the median of the 10 point scale in order to reflect a high rating.

The responses to the three questions were also computed as above and translated into bar charts which, based on the median, which was 10.5, of the total number of respondents, which was 21. To represent a high rating, the responses had to be at 10.5 or above. All the graphs were consolidated into a finding that reflected a validation of the model.

\section{RESULTS/FINDINGS}

The qualitative analysis of the data in phase one of the study, yielded the following findings:

- The resultant demands of globalisation have exerted pressure on organisations to attract, employ, develop and retain the calibre of employee who thinks and acts like an entrepreneur.

- The need for entrepreneurial employees has generated significant interest in the construct, intrapreneurship which has developed as a corollary of entrepreneurship.

- Whereas authors agree that there are four key dimensions of intrapreneurship, this study revealed 5 additional dimensions which are characteristics of intrapreneurship.

- The current performance management systems are not suitable for or effective in managing the calibre of employee required for globally competitive organisations.

- Although the current performance management systems were found to have deficiencies that make them unsuitable for measuring intrapreneurship, as it was established that the Balanced Scorecard created by Norton and Kaplan (1995) and the Total Performance Scorecard created by Rampersad (2003) provided the most suitable (operational) frameworks that could be adapted in order to be integrated with intrapreneurship.

- The key finding of the study is the development of a new generation score card for the management of intrapreneurship, which is referred to in this research as the Intrapreneurial Performance Management Model (IPMM).

The findings of the opinion survey, conducted in phase two, are that; the majority of the respondents felt that:

1. The researcher had identified all the dimensions of intrapreneurship and was correct in differentiating between the true dimensions or characteristics of an intrapreneur and the enablers of intrapreneurship.

2. The approach of the score card measurement is most appropriate for the measurement of intrapreneurship and such approach is of a high value.
3. The conceptual model is highly valid and is of high academic value.

4. They strongly supported the validity of the proposed conceptual model and felt that it would provide a theoretical and practical value.

5. The weighting of the raw scores is highly valid and that these weightings provide a theoretical and practical value.

6. The proposed empirical testing of the conceptual model would be of high theoretical and academic value.

The above-mentioned findings are discussed in detail below.

\section{DISCUSSION}

The analysis of the theory and literature with regard to the construct and content of the concept of entrepreneurship, and thereafter of the emerging concept of intrapreneurship, confirmed that the need for organisations to respond to the requirements of globalisation to produce innovative and competitive products or services to be able to remain competitive and viable, has exerted pressure on them to attract, employ, develop and retain the calibre of employee who thinks and acts like an entrepreneur.

Theinterpretive analysis revealed that this is becauseentrepreneurs, and in the context of this study also intrapreneurs, generally respond to demands and situations by finding innovative solutions to problems, optimising available resources and ensuring more innovative utilisation of resources. Entrepreneurs do this, inter alia, by being innovative, proactive, taking risks, interpreting and exploring new business opportunities and conceiving new combinations of existing resources (see Yamada, 2004).

The study revealed that the pursuit of entrepreneurial orientation and behaviour within organisations has generated considerable interest and has been a subject of research over the past two decades, resulting in the adoption and development of a construct which has become known or referred to as intrapreneurship.

This development of a new construct for the understanding of human behaviour in the work environment, is the result of the recognition that traditionally the term 'entrepreneur' refers to a person who embarks on a new business venture for his or her own account, usually through the establishing of a small (often one-man) business, which may or may not over time develop into a larger corporate. This realisation identified the needs for a new theoretical construct called 'intrapreneur' to identify those employees who demonstrate entrepreneurial behaviour in the corporate environment.

The study further concludes that the promotion and pursuance of intrapreneurship, the new management construct which evolved as the corporate corollary of the commonly held business economics concept of entrepreneurship, suggests a certain pattern of behaviour on the part of the employee in the corporate environment to the execution of his or her tasks. This also applies in his or her attitude towards his work such as, being proactive, innovative and being risk prone, which have emerged as key organisational strategies that positively impact the demands of innovation and competitiveness in the emerging global economic environment.

The above mentioned finding is supported by Antoncic and Hisrich (2003) who refer to intrapreneurship as "...entrepreneurship within an existing business organization..." thereby referring to emergent behaviours in an organization that are related to departures from the customary organisational behaviour patterns. Taylor (2001) concurs that if companies are to survive and succeed, management teams in large companies need to act more like individual entrepreneurs.

Relying on the research of a large number of authors and researchers the study concludes that the definition of intrapreneurship is most practical in terms of what these authors 
and researchers refer to as the 'dimensions of intrapreneurship'. This definition of the construct in terms of certain dimensions has been described by many researchers, inter alia Yamada (2004), as the "...functional view..." of entrepreneurship. It is this functional view that was used in this study for the purpose of explaining the nature and content of the construct 'intrapreneurship'.

In addition, the study determined that most authors agree that there are four 'key' or 'primary' dimensions of intrapreneurship, namely (1) corporate or new business venturing, (2) proactiveness, (3) self-renewal or transformation and (4) competitive aggressiveness. An in depth analysis of the literature revealed, however, that in addition to the above mentioned four dimensions, the following characteristics of the entrepreneur should also be included as dimensions of intrapreneurship, namely (1) strategy, (2) innovativeness, (3) autonomy, (4) risktaking, and (5) team-building.

The veracity of this finding of the necessity to expand the dimensions of intrapreneurship to a total of nine, is supported by the research findings of inter alia Antoncic (2000) and Goosen (2002) who concluded that the construct intrapreneurship comprises of dimensions which exceed the commonly accepted four 'key' or 'primary' dimensions.

Having determined the nature and dimensions of the construct, the study further established that these dimensions have to be allowed proper and practical expression, for intrapreneurship to succeed within organisations. It was found that these dimensions, when allowed proper expression within organisations, translate into a different form, and in that way, play the role of 'facilitating' or 'enabling' the dimensions to be effective. It was determined that the practical effect of intrapreneurship within organisations could be achieved by isolating or identifying these translated dimensions, and referring to them as the "enablers of the (true) dimensions" of intrapreneurship.

The significance of these findings is that the researcher was able, in his analysis of the construct intrapreneurship, to:

- identify and define the following key variables which facilitate or enable the practice of intrapreneurship.

- identify these enablers as being the following: vision, mission, objectives, strategy, culture, structure, risk-taking, team work, autonomy, employee involvement, processes, resources, reward systems, competitiveness, innovativeness, proactiveness, and learning.

- synthesize the dimensions and the enablers into a conceptual model for the measurement of the behaviour of entrepreneurial employees in a corporate environment. Clearly the benefit for the organisations of having such an instrument is that, they will be able to structure themselves in accordance with the conceptual model should they intend to achieve competitiveness;

- identify and define the following key variables which characterise an intrapreneurial employee being innovativeness, proactiveness, autonomy, commitment, risk-taking, competence and ability to learn or being trained.

The importance of the findings mentioned above is that organisations will be able to:

- create environments which are conducive for intrapreneurial behaviour and activities, as the models tabulate the variables which characterise the dimensions of intrapreneurship and their enablers;

- enhance the selection of employees for intrapreneurial programmes as the models specify the attributes of an intrapreneurial employee.

These findings have considerably enhanced the understanding of the dynamics of intrapreneurship and through highlighting the deficiencies of the traditional and contemporary performance management systems, confirm that an unequivocal necessity exists for research into the need for a next generation of performance management systems that would enable or enhance the management of intrapreneurs and the measurement of intrapreneurial behaviour.

The study concludes that the proven deficiencies of current performance management systems, are not suitable for or effective in managing the calibre of employee required for globally competitive organisations even more so with the demands of the new world of work. This applies to even more recently developed approaches to performance management such as the Total Performance Scorecard developed by Rampersad (2003).

Although the current performance management systems were found to have deficiencies that make them unsuitable for measuring intrapreneurship, it was established that the Balanced Scorecard created by Norton and Kaplan (1995) and the Total Performance Scorecard created by Rampersad (2003) provided the most suitable (operational) frameworks that could be adapted in order to be integrated with intrapreneurship.

Their scorecard approach differs from the earlier or more traditional approaches in that they include the key aspects of organisational performance in addition to the performance criteria for individual employees for the measurement of performance in that their approach to performance management is much more 'holistic' than earlier approaches. The score card approach was therefore found to be the most suitable or appropriate for integrating the dimensions of intrapreneurship, as all aspects of organisational functioning should embrace intrapreneurship if innovation and competitiveness were to be achieved.

This discovery facilitated the synthesis of the dimensions and enablers of intrapreneurship into a list of variables to be used in a new measuring instrument based on the conceptual structure of the above mentioned scorecard system. This led to the development of a new generation score card, which will henceforth be referred to in this research report as the Intrapreneurial Performance Management Model (IPMM).

This model was developed as a conceptual model only as it had not been based on empirical evidence. Obviously, for the new model to gain practical value and usage it will need to be subjected to empirical investigation in order to determine the comparative statistical or arithmetic values for the variables, as well as the correlation dynamics of the variables in the model.

This conceptual model is meant, therefore to provide a theoretical and scientific conceptualization of the integration of the said variables into the score card structures. The intention is to contribute a research framework for future empirical research into the practical measurement of intrapreneurial behaviour within organizations, as well as the extent to which organizations facilitate, support and promote intrapreneurial behaviour. As the model is a consequence of the consolidation of in depth literature analysis, it is further intended to contribute to the theoretical expansion of the construct as its findings may trigger additional need for further research on the construct.

From the interpretive analysis of the dynamics of intrapreneurship it was also found that variables, both the intrapreneurial dimensions and the enablers, will of necessity have different values (in relation to each other) in different situations, and for different types of organization, in terms of technology, markets, products and processes. Consequently it was found that the Intrapreneurial Performance Management Model will of necessity have to be a 'situational model,' in that it is not intended to be generalized but to be adapted to suit variant organisational sizes, industries, and technological bases.

The basic premise from which the research departs is that, while the founding construct is universally applicable, the model will in practice have to be adapted to accommodate the varying 
dynamics of different technologies and operating systems, varying complexities created by size and structure, culture, climate, and the impact of market differences, supplier bases and resource availability. The study also determined that for the model to be successful, it has to function primarily through four separate and discrete (subordinate) score cards, each dealing with a different component of the organisational system. Each would eventually have to be integrated into an overall (super-ordinate) score card measuring instrument, that will measure or evaluate the complete organisational system with the view to determining its' viability for competitiveness and survival in the new world of work. The four subordinate scorecards are listed below:

1. organisational score card,

2. employee score card,

3. client score card and

4. supplier score card.

The above score cards were designed to measure the expression of the nine dimensions of intrapreneurship together with their enablers.

The study determined that to ensure the structural feasibility of the conceptual model and also to create an operational framework against which further empirical research aimed at determining the empirical values of the conceptual model as a measuring instrument could be developed, use of the criteria (a) what to measure, and (b) how to measure, would considerably enhance the structural dynamics of the model. Using these criteria, the model will theoretically be able to 'measure' variables which determine the intrapreneurial capacity of the organisation. The consequential benefit of using the model and its measuring instruments or criteria is that, organisations may, based, on the outcome of the measure (through the model) devise strategies for improvement in order to achieve competitiveness.

It was further determined that, the evaluation of the performance of the employee and that of the organisation, in terms of the above stated criteria of the model would have to be done by means of a Likert-type 5-point rating scale. The Likert rating scale is commonly acknowledged and applied in social sciences, because it allows the categorisation of the raw scores given by each assessor into intervals of sufficient size or scope to allow for adequate differentiation across a continuum from zero to 100. As the Intrapreneurial Performance Management Model is a conceptual model, the ratings, will not be exact statistical intervals, but will rather be conceptual indications of the measures that can be applied. The actual statistical measures will have to be determined by means of an empirical investigation, and probably by means of the development of a properly researched stochastic or statistical model, once the veracity and viability of the conceptual model has been determined.

Another finding is that as the model is aimed primarily at measuring the expression of the nine dimensions of intrapreneurship, in order for it to function properly, it had to recognise the varying and complex nature in which these dimensions manifest themselves within an organisation. As a consequence it was established that such recognition could be achieved by differentiating between the true dimensions and their enablers, in each score card of the model. Furthermore, the study concludes that the recognition of the varying and complex nature of the manifestation of the dimensions and the differences in size, nature of operation and industry, required the provision of the weighting of the scores resulting from the measuring instruments of the scorecards.

The concept of weighting is used in scientific methodological language to refer to a process of translating 'absolute raw scores' into 'relative weighted scores.' This is done to ensure that a comparator, or basis of equivalent comparisons, can be established: 'to compare apples with apples'. Weighting can also be referred to as a process of translating raw scores which are not comparable to comparable values. Owing to the variance in the relative value of each of the dimensions and their enablers in the respective score cards, it was found that weighting would then provide a fair measure of comparability.

Once the isolation and differentiation of dimensions and enablers was achieved, it was found that the consolidation of the measuring instruments on the conceptual model could be achieved by referring to all the dimensions and enablers as 'variables'. This would facilitate the application of the model as all the measuring instruments would refer to each factor requiring measurement, as a variable as a variable.

The significance of the Intrapreneurial Performance Management Model is that it is able to integrate the measurement of intrapreneurship and organisational performance, including that of employees, into a single measuring framework. The value for organisations is that they will be able to conduct analysis of all the components of their business in a structured manner. The results of such measurement would determine the extent to which organisations have the capacity to respond to the requirements of globalisation.

The conceptual nature of the model was found to pose some challenges as, although it is based on extensive literature review of the construct intrapreneurship, its measuring instruments and ratings are not exact statistical measures or intervals, but rather conceptual indications of the measures that can be applied. It would therefore have to be subjected to an empirical investigation in order to determine the veracity of its values.

Although the model which has emerged from this study is a conceptual one, a questionnaire was developed to elicit the opinion of a sample of respondents. The aim was to determine the functionality and feasibility of the model in so far as its academic and theoretical value, practical value and the value of its scorecards, proposed weighting of scores, and recommended empirical value can be determined. This questionnaire was administered to a sample of 21 respondents (comprising of academics and students of entrepreneurship) from the University of Western Cape, in South Africa.

\section{Value of the Study}

In summary it can be stated that the study makes the following key contributions to the field of intrapreneurship, human resources management, and industrial psychology.

1. Firstly, it consolidates various research findings and literature on the construct intrapreneurship and expands on the findings of previous studies on the construct by discovering additional dimensions that characterise intrapreneurship. This is despite previous propositions that intrapreneurship has four dimensions. The isolation of the dimensions and the enablers of intrapreneurship is a major contribution, as through the two conceptual models on intrapreneurship, it will: (i) enhance the identification and definition of the variables that characterise the true nature of intrapreneurship, and (ii) enhance the identification and definition of the variables which enable intrapreneurship by the employee or organisation.

2. A further contribution is the developing of two conceptual models of intrapreneurship that depict the dimensions of intrapreneurship and characteristics of an intrapreneurial organisation as well as those of an employee. These models will contribute towards further studies on the development of the construct, as through the variables depicting the true dimensions and their enablers will provide the empirical basis for the extrapolation of the true value of these variables on intrapreneurship.

3. The study has contributed towards enhancing the developments and future research on the efficacy of performance management by highlighting the deficiencies of the current performance management systems and the future challenges thereof within the context of the new world of work. 
4. Finally, through the development of a conceptual performance management model, a sound scientific basis, albeit conceptual at this stage, has been provided for the measurement of intrapreneurship in the corporate environment in the new world of work. This will also provide a basis for further empirical research into determining the mathematical or arithmetic value of a measure of intrapreneurship and performance.

\section{Recommendations}

In light of the foregoing findings and limitations, it is the recommended that an empirical investigation be conducted to determine the true value of the measures of the Intrapreneurial Performance Management Model. In addition, future research on the application and true value of the measures of the model should recognise the differences in the values of the dimensions of intrapreneurship and attempt to determine the true or statistical value of those differences including that of weightings.

It should be noted that any research conducted on the practical value of intrapreneurship, should first extrapolate its true characteristics and the variables which enhance its application within the organisation. These having been established, it would be imperative to determine empirically the value of those dimensions and their enablers within organisations. The human factor behind the success of intrapreneurial endeavours also needs to be further explored.

Furthermore it is recommended that once the values of the dimensions have been determined, the Conceptual Model should be tested to determine its theoretical/academic value and its practical value.

\section{REFERENCES}

Andersen, B., \& Fagerhaug, T. (2002). Performance measurement explained: designing and implementing your state of the art system. Wisconsin: Quality Press.

Armstrong, M. \& Baron, A. (2005). Managing performance: Performance management in action. London: Chartered Institute of Personnel and Development House.

Audretsch, D.B. Sustaining innovation and growth: policy for entrepreneurship Industry and Innovation. Sydney: Sep 2004 Vol.11, Iss.3; p.167.

Antoncic, B (2000) Intrapreneurship: Construct refinement and an Integrative model Development. Unpublished PhD Thesis, Case Western Reserve University.

Antoncic, B., \& Hisrich, R.D. Intrapreneurship modelling in transition economies: A comparison of Slovenia and the United States. Journal of Developmental Entrepreneurship. Norfolk: Apr 2000.Vol.5, Iss. 1; pg. 21.

Antoncic, B., \& R. D. Clarifying the intrapreneurship concept. Journal of Small Business and Enterprise Development Bradford: 2003. Vol. 10, Iss. 1, p.7.

Antoncic, B., \& Hisrich, R. D. Corporate entrepreneurship contingencies and organizational wealth creation. The Journal of Management Development. Bradford: 2004.Vol.23, Iss. $5 / 6$; pg. 518.

Barrett, H., Balloun, J.L., Weinsten, A. Marketing mix factors as moderators of the corporate entrepreneurship - business performance relationship - a multistage, multivariate analysis. Journal of Marketing Theory and Practice. Statesboro: Spring 2000.Vol.8, Iss. 2; pg. 50.

Beatham, S., Anumba, C., Thorpe, T., Hedges, I. An integrated business improvement system (IBIS) for construction. Measuring Business Excellence. Bradford: 2005.Vol.9, Iss. 2; pg. 42, 14 pgs

Bititci, U. S., Mendibil, K., Martinez,V., \& Albores, P. Measuring and managing performance in extended enterprises. International Journal of Operations \& Production Management. Bradford: 2005.Vol.25, Iss. 3/4; pg. 333,21 pgs
Bogdan, R.C., \& Biklen, S.K. (2003). Qualitative research for education. An introduction to theory and methods. Boston: Allyn \& Bacon.

Bostjan A., Robert D Hisrich. Corporate entrepreneurship contingencies and organizational wealth creation. The Journal of Management Development. Bradford: 2004, Vol 23, Iss. $5 / 6$ p. 518 .

Bryman, A. (2004). Social Research Method. New York: Oxford University.

Busco, C., Frigo, M. L., Giovannoni, E., Riccaboni, A., \& Scapens, R.W. Integrating global organizations through performance measurement systems. Strategic Finance. Montvale: Jan 2006. Vol.87, Iss. 7; pg. 30.

Coulson-Thomas, C. Individuals and enterprise: developing intrapreneurs for the new millennium. Industrial and Commercial Training Volume 31 Number 71999 pp. 258-261.

Crandon, D.S., \& Merchant, K.A. Principles to Guide the Development and Use of Effective Performance Measures Performance Improvement. Silver Spring: Feb 2006.Vol.45, Iss. 2; pg. 17,7pgs.

Christensen, K.S. Enabling intrapreneurship: the case of a knowledge-intensive industrial company. European Journal of Innovation Management Volume 8 Number 32005 pp. 305-322.

Dehne, T. The corporate culture and customer-inspired innovation. R \& D. Highlands Ranch: May 2003. Vol. 45, Iss. 5; pg. 11.

De Waal, A.A. (2002). Quest for balance: The human element in performance management systems. New York: John Wiley \& Sons.

Eesley, D.T., \& Longenecker, C.O. Gateways to Intrapreneurship Industrial Management. Norcross: Jan/Feb 2006.Vol.48, Iss. $1 ;$ pg. 18.

Echols, A. E., \& Christopher P. Neck, C.P. The impact of behaviors and structure on corporate entrepreneurial success. Journal of Managerial Psychology. Bradford: 1998. Vol. 13, Iss. 1/2; pg. 38

Equist, C., Hommen, L., \& Mckelvey, M. (2001) Innovation and employment: Process versus product innovation: Massachusetts: Edward Elgas Publishing.

Fattal, T. Intrapreneurship at work. CMA Management. Hamilton: Nov 2003.Vol.77, Iss. 7; pg. 14.

Fitzsimmons, J.R., Douglas, E.J., Antoncic, B., \& Hisrich, R.D. Intrapreneurship in Australian Firms. Journal of the Australian and New Zealand Academy of Management. Lindfield: 2005. Vol.11, Iss. 1; pg. 17.

Goosen, C. J. (2002) Key factor intrapreneurship: The development of a systems model to facilitate the perpetuation of entrepreneurship in the larger South African Organisation Unpublished PhD Theses: University of Stellenbosch.

Graham, J. Developing a Performance-Based Culture. The Journal for Quality and Participation. Cincinnati: Spring 2004.Vol.27, Iss. 1 ; pg. 4-5.

Greco, S., Caggiano, C., \& Ballon, M. 'I was seduced by the new economy'. Inc. Boston: Feb 1999.Vol.21, Iss. 2; pg. 34.

Grogan, J. (2001). Workplace law. Cape Town: Juta.

Hale, R., \& Whitlam, P. (2000) Powering up performance management: An integrated approach to getting the best from your people. Gower Publishing: Hampshire.

Hua Tan, K., Platts, K., \& Noble, J. Building performance through in-process measurement: Toward an "indicative" scorecard for business excellence. International Journal of Productivity and Performance Management. Bradford: 2004.Vol.53, Iss. 3/4;pg. 233.

Jacobs, H., \& Kruger, S. (2001) Establishing an intrapreneurial orientation as strategy: a framework for implementation. Acto Commercii, Vol. 1

Kaplan. R. S., \& Norton. D.P. The Balanced Scorecard: Measures that drive performance. Harvard Business Review. July-August 2005.

Kuratko, D .F., \& Goldsby, M. G. (2004). Corporate Entrepreneurs or Rogue middle Managers? A framework for Ethical Corporate Entrepreneurship. Journal of Business Ethics, 55: 13-30. 
Kuratko, D. F.; \& Hodgetts, R. M. (2004). Entrepreneurship: theory, process, and practice. Ohio: Thomson Learning.

Kuratko, D.F., Ireland, R.D., \& Hornsby, J.S. Improving firm performance through entrepreneurial actions: Acordia's corporate entrepreneurship strategy. The Academy of Management Executive. Briarcliff Manor: Nov 2001.Vol.15, Iss. 4 ; pg. 60.

Lawn, J. The Challenge of Intra-preneurship. Food Management. Cleveland: Oct 2005.Vol.40, Iss. 11; pg. 10.

Lawrie, G., Cobbold, I.,\& John Marshall. Corporate performance management system in a devolved UK governmental organisation: A case study. International Journal of Productivity and Performance Management. Bradford: 2004. Vol.53, Iss. 3/4; pg. 353.

lLewis, J., Wright, P.C., \& Geroy, G.D. Managing human capital: The study of a self-managed group venturing into the digital economy. Management Decision. London: 2004.Vol.42, Iss. 1/2; pg. 205.

Likert, R. (1967). The Human Organisation. New York: Mc GrawHill.

Madison, G. B. (1990). The Hermeneutics of Postmodernity: Figures and Themes. Bloomington: Indiana University Press.

Manion, J. Enhancing career marketability through intrapreneurship. Nursing Administration Quarterly. Frederick: Winter 2001.Vol.25, Iss. 2; pg. 5.

Meyer, M. W., (2002) Rethinking performance measurement: Beyond the balance scorecard. Cambridge: Cambridge University Press.

Michelle, C. Becoming an entrepreneur. The Canadian Nurse. Apr 2005.Vol.101, Iss. 4; pg. 14.

Miller, D.C., \& Salkind, N.J. (2002). Handbook of Research Design \& Social Measurement. California: Sage Publications.

Mouton, J (1996). Understanding social research. Pretoria: Van Schaik.

Neuman, W.L (2000). Social Research Methods: Qualitative and quantitative approaches. Boston: Allyn \& Bacon.

Neuman, W.L (2003). Social Research Methods: Qualitative and quantitative approaches. Boston: Allyn \& Bacon.

O'Leary-Collins, M. A powerful business model for capturing innovation. Management Services. Enfield: Summer 2005.Vol.49, Iss. 2; pg. 37, 3 pgs Partington, D. (2002). Essential skills for management research. London: Sage Publications.

Olmsted, L. Non-stop innovation Inc. Boston: Jul 2005.Vol.27, Iss. 7; pg. 34.

Rampersad, H. K. (2003) Total Performance Scorecard: Redefining management to achieve performance with integrity. Amsterdam: Butterworth-Heinemann.

Rebecca, A. The relationship of vertical and horizontal individualism and collectivism to intrapreneurship and organizational commitment. Leadership \& Organization Development Journal. Bradford: 1997.Vol.18, Iss. 4; pg. 179.

Robinson, M. The ten commandments of entrepreneurs. New Zealand Management. Auckland: Dec 2001.Vol.48, Iss.11; pg.95.

Robson, I. Implementing a performance measurement system capable of creating a culture of high performance International Journal of Productivity and Performance Management. Bradford: 2005.Vol.54, Iss.1/2; pg.137.

Rodgers, K. Stepping up performance management. Personnel Today. Sutton: Jun 7, 2005. pg. 20.

Russell, R.D. Developing A Process Model Of Intrapreneurial Systems: A Cognitive Mapping Approach. Entrepreneurship: Theory \& Practice, 10422587, Spring99, Vol. 23, Issue 3.

Salavou, H. The concept of innovativeness: should we need to focus? European Journal of Innovation Management. Bradford: 2004.Vol.7, Iss. 1; pg. 33

Saunders, M., Lewis, P., Thornhill, A. (2003). Research methods for business students. Ashford: Gosport.
Schindehutte, M., Morris, M. H., \& Kuratko, D. F. Triggering events, corporate entrepreneurship and the marketing function. Journal of Marketing Theory and Practice. Statesboro: Spring 2000.Vol.8, Iss. 2; pg. 18.

Schwandt, T.A. (2003). Interpretivism, hermeneutics, and constructionism. In Denzin, N.K., \& Lincoln, Y.S. (2003). Handbook of qualitative research. London: Sage Publications.

Shurink, W.J. (2004c). Lecture Three: Considerations when choosing a qualitative style of research. Introducing key features of an interpretive approach to social science. University of Johannesburg 27-28

Silverman, D. (2001). Interpreting qualitative data; methods for analysing talk, text, and interaction. London: Sage Publications.

Slabbert, J.A., Prinsloo, J.J., Swanepoel, B.J., \& Backer, W. (2003). Managing employment relations in South Africa. Durban: Butterworths.

Smith, M. Performance Management Methodology Business Credit. New York: Nov/Dec 2005.Vol.107, Iss.10; pg. 54.

Stevens, T. Idea dollars Industry Week. Cleveland: Feb 16, 1998. Vol.247, Iss. 4; pg. 47.

Sundbo, J. Empowerment of employees in small and mediumsized service firms. Employee Relations. Bradford: 1999.Vol.21, Iss. 2; pg. 105.

Tangen, S. Improving the performance of a performance measure. Measuring Business Excellence. Bradford: 2005.Vol.9,Iss. 2; pg. 4.

Taylor, B. From corporate governance to corporate entrepreneurship. Journal of Change Management. London: Dec 2001.Vol.2, Iss. 2; pg. 128.

Templer, A. The HRM response to global changes in employment relationships. Management Research News. Patrington: 2000. Vol.23, Iss.2-4. p 75.

Thompson, J.L. Innovation through people. Management Decision. London: 2004.Vol.42, Iss. 9; pg.1082.

Thornberry, N. E. Corporate entrepreneurship: Teaching managers to be entrepreneurs. The Journal of Management Development. Bradford: 2003.Vol.22, Iss.4; pg. 329.

Tosi, H.L., \& Mero, N.P. (2003). The fundamentals of organisational behaviour: What managers need to know. Blackwell Publishing: Oxford.

Ulrich, D. (1997). Human Resources Champions: The next agenda for adding value and delivering results. USA: Harvard Business School.

Verweire, K., \& Van den Berghe (2004). Integrated performance management: New hype or new paradigm. London: Sage Publications

Wade, D. \& Recardo, R. (2001). Corporate performance management. Woburn: Butterworth-Heinemann.

Whittaker; L (2001) Information systems evaluation: A post dualist interpretation. Unpublished PhD Thesis, University of Pretoria.

Williams, K. How Does Your Company Measure Performance? Strategic Finance. Montvale: Dec 2004. Vol. 86, Iss. 6; pg. 17.

Wilkes, J. Leading and lagging practices in performance management. Measuring Business Excellence. Bradford: 2005. Vol.9, Iss.3; pg. 41.

Williams, R. S (2000). Performance management: Perspectives on employee performance. Cornwall: T.J International.

Williams, K. How Does Your Company Measure Performance? Strategic Finance. Montvale: Dec 2004.Vol.86, Iss.6; pg. 17.

Wunderer, R. Employees as "co-intrapreneurs" a transformation concept. Leadership \& Organization Development Journal Bradford 2001.Vol 22, Iss. 5'/6, p.193.

Yamada, J. A multi-dimensional view of entrepreneurship: Towards a research agenda on organisation emergence. The Journal of Management Development. Bradford: 2004, Vol 23, Iss. $3 / 4$ p.329.

Zhao, F. Exploring the synergy between entrepreneurship and innovation International Journal of Entrepreneurial Behaviour \& Research. Volume 11 Number 12005 pp. 25-41 